\title{
Effects of ovariectomy in antioxidant defence systems in right ventricle of female rats with pulmonary arterial hypertension induced by monocrotaline
}

\begin{tabular}{|c|c|}
\hline Journal: & Canadian Journal of Physiology and Pharmacology \\
\hline Manuscript ID & cjpp-2016-0445.R2 \\
\hline Manuscript Type: & Article \\
\hline Date Submitted by the Author: & 20-Mar-2017 \\
\hline Complete List of Authors: & $\begin{array}{l}\text { Siqueira, Rafaela; Universidade Federal do Rio Grande do Sul, Research } \\
\text { Colombo, Rafael; Universidade Federal do Rio Grande do Sul, Fisiologia } \\
\text { Conzatti, Adriana; UFRGS, Physiology } \\
\text { De Castro, Alexandre; Centro Universitario Ritter dos Reis } \\
\text { Carraro, Cristina; Universidade Federal do Rio Grande do Sul } \\
\text { Tavares, Angela ; Centro Universitario Ritter dos Reis } \\
\text { Fernandes, Tania; UFRGS, Physiology } \\
\text { Araujo, Alex Sander; UFRGS, Physiology } \\
\text { Belló-Klein, Adriane; UFRGS, Physiology }\end{array}$ \\
\hline $\begin{array}{r}\text { Is the invited manuscript for } \\
\text { consideration in a Special } \\
\text { Issue?: }\end{array}$ & N/A \\
\hline Keyword: & $\begin{array}{l}\text { oxidative stress, estrogen, hemeoxygenase, thioredoxin, pulmonary } \\
\text { hypertension }\end{array}$ \\
\hline
\end{tabular}


Effects of ovariectomy on antioxidant defence systems in the right ventricle of female rats with pulmonary arterial hypertension induced by monocrotaline

Rafaela Siqueira; Rafael Colombo; Adriana Conzatti; Alexandre Luz de Castro; Cristina Campos Carraro; Angela Maria Vicente Tavares; Tânia Regina Gattelli Fernandes; Alex Sander da Rosa Araujo; Adriane Belló-Klein

Laboratory of Cardiovascular Physiology and Reactive Oxygen Species, Physiology Department, Institute of Basic Health Science (ICBS), Federal University of Rio Grande do Sul (UFRGS), Porto Alegre, RS, Brazil

Corresponding author:

Dr. Adriane Belló-Klein

Laboratory of Cardiovascular Physiology and Reactive Oxygen Species, Physiology Department, Institute of Basic Health Science (ICBS), Federal University of Rio Grande do Sul (UFRGS), Rua Sarmento Leite, 500 - CEP 90050-170, Porto Alegre, RS, Brazil, Tel.: +55 (51) 3308-3621.

Email: belklein@ufrgs.br 


\begin{abstract}
The aim of this study was to evaluate the impact of ovariectomy on oxidative stress in the right ventricle $(\mathrm{RV})$ of female rats with pulmonary arterial hypertension $(\mathrm{PAH})$ induced by monocrotaline (MCT). Rats were divided into four groups ( $n=6 /$ group): sham $(\mathrm{S})$, sham + MCT (SM), ovariectomized (O), and ovariectomized + MCT (OM). MCT (60 mg/kg i.p) was injected 1 week after ovariectomy or sham surgery. Three weeks after,, echocardiographic analysis and RV catheterisation were performed. RV morphometric, biochemical, and protein expression analysis through western blotting were done. MCT promoted a slight increase in pulmonary artery pressure, without differences between the SM and OM groups, but did not induce RV hypertrophy. RV hydrogen peroxide increased in the MCT groups, but SOD, CAT, and GPx activities were also enhanced. Non-classical antioxidant defenses diminished in ovariectomized groups, probably due to a decrease in the nuclear factor Nrf2. Hemoxygenase-1 and thioredoxin-1 protein expression was increased in the OM group compared to SM, being accompanied by an elevation in the estrogen receptor $\beta$ (ER- $\beta$ ). Hemoxygenase-1 and thioredoxin-1 may be involved in the modulation of oxidative stress in the OM group, and this could be responsible for attenuation of PAH and RV remodeling.
\end{abstract}

Keywords: Oxidative stress, estrogen, hemoxygenase, thioredoxin, pulmonary hypertension 


\section{Introduction}

Pulmonary arterial hypertension (PAH) is characterized by an increase in mean pulmonary artery pressure (Rabinovitch $2011 a$ ), due to pulmonary vascular remodelling that leads to an imbalance between excessive vasoconstrictors and low levels of vasodilators (Giaid et al. 1993; Waxman and Zamanian 2013). Together, these factors, contribute to an increased pulmonary vascular resistance, which may cause an increment in the afterload imposed on the right ventricle (RV) (Rabinovitch $2012 b$ ). This increased afterload promotes adaptations in RV, ranging from RV hypertrophy to $\mathrm{RV}$ failure and premature death.

The prevalence of PAH is higher in females than in males (Badesch et al. 2010). Although there is an impact of gender in this pathophysiology, the mechanisms involved are still not well understood (Austin et al. 2013). Even though females are more affected by PAH, survival after diagnosis is higher in females than in males. One mechanism proposed to explain this outcome is a differential RV adaptation to $\mathrm{PAH}$ relative to gender (Humbert et al. 2010).

It is believed that one of the most important differences observed between males and females is the protective effect of estrogen in animal models of PAH (Martin and Pabelick 2014). The major biological estrogen effects on cells occur through estrogen receptors $\alpha(E R-\alpha)$ and $\beta($ ER $-\beta)$, both expressed in the cardiovascular system (Umar et al. 2011). Several factors may regulate the expression, activity, and biological effects of these receptors. Furthermore, estrogen effects can also be mediated through ERindependent pathways (Raghvendra et al. 2004).

Estrogen administration has been associated with an improvement in PAH in animal models of hypoxia and monocrotaline (Farhat et al. 1993; Lahm et al. 2012). This cardioprotective effect may result from the direct effect of estrogen as a free- 
radical scavenger (Ruiz-Larrea et al. 1997). This hormone may also play an antioxidant role, since it increases gene expression of antioxidant proteins, such as hemoxygenase, superoxide dismutase (SOD) and thioredoxin (Massafra et al. 2000). It has been reported that the genomic effect of estrogen can be determined by the activation of nuclear factor (erythroid-derived 2)-like factor 2 (Nrf2), even though the mechanism by which this occurs remains unclear (Zhang et al. 2013).

There is an association between estrogen withdrawal and antioxidant defence system impairment (Bellanti et al. 2013). After menopause, the production of reactive oxygen species (ROS) increases, leading to oxidative stress. Oxidative stress is involved in PAH (Takano et al. 2003), since ROS can modulate vascular tone, smooth muscle cell proliferation, vascular remodelling, and apoptosis. ROS levels are directly associated with the progression from RV hypertrophy to heart failure (Tabima et al. 2012). However, there are some aspects about the influence of estrogen on RV oxidative stress in female rats with PAH that have not yet been explored. Therefore, this study aimed to evaluate the impact of ovariectomy on oxidative stress and adaptations of the antioxidant system in the RV of female rats with PAH.

\section{Material and methods}

\section{Ethical approval}

All animal procedures used in this study were in accordance with institutional guidelines and the Guide for the Care and Use of Laboratory Animals (U.S. Department of Health and Human Services, NIH Publication No. 86-23) and were approved by the Ethics Committee on Animal Use (CEUA) of the Federal University of Rio Grande do Sul (project number 21372). 


\section{Animals and treatments}

Female Wistar rats $(n=24)$, weighing $180 \pm 50 \mathrm{~g}$, were obtained from the Center of Reproduction and Experimentation of Laboratory Animals (CREAL) of the Federal University of Rio Grande do Sul. The rats were housed in plastic cages, four animals in each cage, and received water and food ad libitum. They were maintained under standard temperature and humidity conditions, and light/dark cycles of $12 \mathrm{~h}$. Four experimental groups ( $n=6$ per group) were established by random distribution of animals: a) sham (S): submitted to ovariectomy simulation surgery; b) sham + monocrotaline (SM): submitted to ovariectomy simulation surgery and monocrotaline injection; c) ovariectomized (O): submitted to bilateral ovariectomy; and d) ovariectomized + monocrotaline $(\mathrm{OM})$ : submitted to ovariectomy and monocrotaline injection. Induction of PAH occurred 1 week after ovariectomy or sham surgery with a single intraperitoneal injection $(60 \mathrm{mg} / \mathrm{kg}$ ) of monocrotaline (Sigma Chemicals, St. Louis, MO) or the same volume of saline (Tofovic et al. 2006). The overall duration of the protocol was three weeks. At the end of the protocol, the animals were anaesthetized with ketamine (90 mg/kg i.p.) and xylazine (10 mg/kg i.p.) and killed afterwards by cervical dislocation.

\section{Bilateral ovariectomy}

Rats were anesthetized with ketamine (90 mg/kg i.p.) and xylazine $(10 \mathrm{mg} / \mathrm{kg}$ i.p.) for bilateral ovariectomy. A small abdominal incision was made and ovaries were located. A silk thread was tightly tied around the oviduct, the oviduct was sectioned and ovaries were removed (Campbell and Febbraio 2002). In the S and SM groups, the same procedure was carried out, but without the removal of the ovaries. 


\section{Determination of the estrous cycle}

Estrous cycle determination was performed after the end of the experimental protocol in animals that did not undergo ovariectomy. The cycle for each animal was determined by the observation of vaginal smear. The slides were compared with the findings of Marcondes et al. (2002). All non-ovariectomized animals were killed during the diestrus phase.

\section{Echocardiography assessment}

Echocardiographic images were obtained using the two-dimensional mode and a pulsed Doppler (Ultrasound System Philips HD7, Andover, MA, USA) with a linear probe (L12-3; Philips). The relationship between the acceleration time (AT) to ejection time (ET), calculated from the pulmonary artery flow, was evaluated alongside stroke volume (SV) and cardiac output (CO) of the RV. For the calculation of the stroke volume, the following formula was used: VS = cross-sectional area of the pulmonary artery (AST) $x$ full-time flow rate through the pulmonary artery (IVA); where: AST = (systolic pulmonary artery diameter/2) $2 \times 3.14$. To calculate $\mathrm{CO}$, the following formula was used: $\mathrm{CO}=\mathrm{VS} \mathrm{x}$ heart rate $(\mathrm{HR})$; where: $\mathrm{HR}=60 / \mathrm{RR}$, interval measured during flow through the pulmonary artery (Rudski et al. 2010; Urboniene et al. 2010).

\section{Hemodynamic evaluation}

For hemodynamic evaluation, the right jugular vein was exposed and a polyethylene catheter (PE-50) was introduced into the atrium and right ventricle. The catheter was connected to a pressure transducer (strain-gauge transducer, Narco Biosystems RP-155, Houston, Texas, USA) and coupled to a signal amplifier (HP 8850C Pressure Amplifier) for monitoring of the right ventricular systolic pressure 
(RVSP) and end-diastolic pressure (RVEDP). Analogue signals were digitized (Windaq - Data Acquisition System, PC 486) with a sampling rate of $1000 \mathrm{~Hz}$ (Ludke et al. 2010). The RVSP was used in order to estimate systolic pulmonary artery pressure, as RVSP is similar to systolic pulmonary artery pressure. Pulmonary artery pressure (PAP) was estimated using the following equation: Mean PAP $(\mathrm{mmHg})=0.61 \mathrm{x}$ systolic PAP + 2 (Chemla et al. 2004; Koskenvuo et al. 2010).

\section{Morphometric analysis}

Cardiac hypertrophy was calculated by the relationship between the right ventricular mass and body weight $(\mathrm{mg} / \mathrm{g})$, and the right ventricular mass and tibia length $(\mathrm{mg} / \mathrm{mm})(\mathrm{Hu}$ et al. 2003). The uterus was removed and its wet weight was quantified to confirm the efficacy of ovariectomy (Campbell and Febbraio 2002).

\section{Hydrogen peroxide concentration}

The assay was based on horseradish peroxidase-mediated oxidation of phenol red by hydrogen peroxide. A slice of the right ventricle was homogenized in potassium chloride $(1.15 \% \mathrm{w} / \mathrm{v})$ and phenyl methyl sulphonyl fluoride (PMSF; $20 \mathrm{mmol} / \mathrm{L})$ and centrifuged (3000 rpm for $20 \mathrm{~min}$ at $\left.0-4^{\circ} \mathrm{C}\right)$. The supernatant was used for further analysis. To determine the concentration of hydrogen peroxide (nmol/mg tissue), a standard curve with hydrogen peroxide concentrations of 10,20 and $30 \mu \mathrm{M}$ was performed. After addition of hydrogen peroxide to the standards, and the supernatant of the RV to the microplate wells, the samples were incubated with a buffer containing phenol red, dextrose, and horseradish peroxidase. After incubation, $1 \mathrm{~N} \mathrm{NaOH}$ was added, and readings were taken at $610 \mathrm{~nm}$ (Pick and Keisari 1980). 


\section{Nitric oxide synthase (NOS) activity}

NOS activity was evaluated in RV homogenates by measuring the conversion of oxyhemoglobin $(\mathrm{HbO} 2)$ in methemoglobin induced by $\mathrm{NO}$, as described by Valdez et al. (2005). The reaction medium was composed of (in mmol/L): $\mathrm{CaCl}_{2}$ 1.8; $\mathrm{KCl}$ 2.7; $\mathrm{MgCl}_{2}$ 0.23; $\mathrm{NaCl} 137 ; \mathrm{NaH}_{2} \mathrm{PO}_{4}$ 3.6; glucose 5.0; HEPES 10; $\mathrm{pH} 7.4$, and contained 2 $\mathrm{mol} / \mathrm{L} \mathrm{HbO}_{2}$ and $1 \mathrm{mmol} / \mathrm{L}$ L-arginine. NOS activity was expressed in nmol $\mathrm{NO} / \mathrm{min} / \mathrm{mg}$ protein.

\section{Antioxidant enzyme activities}

Antioxidant enzyme activities were determined in RV homogenates. Superoxide dismutase (SOD) activity determination was based on the inhibition of the superoxide radical reaction by pyrogallol (Marklund 1985). SOD activity was expressed as units/mg of protein. Absorbance changes were followed at $420 \mathrm{~nm}$ for $2 \mathrm{~min}$. Catalase (CAT) activity was determined by following the decrease in hydrogen peroxide absorbance at $240 \mathrm{~nm}$. CAT activity was expressed in pmol/mg protein (Aebi 1984). The glutathione peroxidase (GPx) assay was based on the consumption of NADPH and was measured at $340 \mathrm{~nm}$. GPx activity was reported in nmol/min/mg protein (Flohé and Gunzler 1984).

\section{Protein oxidation measurement}

RV samples were incubated with $10 \mathrm{mmol} / \mathrm{L}$ dinitrophenylhydrazine (DNPH) in $2.5 \mathrm{~mol} / \mathrm{L} \mathrm{HCl}$ at room temperature for $1 \mathrm{~h}$. Trichloroacetic acid (20\%) was added, and precipitated proteins and pellets were washed with ethanol/ethyl acetate $(1: 1 \mathrm{v} / \mathrm{v})$. The final precipitates were dissolved in $6 \mathrm{~mol} / \mathrm{L}$ guanidine hydrochloride, and read at 360 nm. Results were expressed in nmol/mg protein (Reznick and Packer 1994). 


\section{Lipid peroxidation assay}

The evaluation of lipid peroxidation was based on a method that consists of adding a synthetic organic hydroperoxide (tert-butyl hydroperoxide) to the RV homogenates and monitoring chemiluminescence. Chemiluminescence was measured using a beta counter (LKB Rack Beta Liquid Scintillation Spectrometer-1215, LKB Produkter AB, Bromma, Sweden) with the coincidence circuit disconnected, and using the tritium channel. Results were expressed in counts per seconds (cps) per mg protein (Gonzalez Flecha 1991).

\section{Determination of protein concentration}

Protein concentration (mg protein $/ \mathrm{mL}$ ) was measured by the method of Lowry et al. (1951), using bovine serum albumin as standard.

\section{Western blot analysis}

$\mathrm{RV}$ was homogenized and centrifuged at $8000 \mathrm{xg}$ for $15 \mathrm{~min}$ at $4^{\circ} \mathrm{C}$ to remove the nuclei and cell debris. Supernatants were used for the assay. Protein $(48 \mu \mathrm{g})$ was subjected to one-dimensional SDS-PAGE in a discontinuous system using different concentrations of separating gel and stacking gel (Laemmli 1970). The separated proteins were transferred electrophoretically to PVDF membranes, using a buffer ( $\mathrm{pH}$ 8.2, Tris $25 \mathrm{mmol} / \mathrm{L}$, glycine $192 \mathrm{mmol} / \mathrm{L}$, and SDS 0.1\%) in a cooled Bio-Rad TransBlot unit (Bio-Rad, São Paulo, SP, Brazil). Non-specific protein binding was blocked by a 1-h incubation with non-fat milk in Tris buffer. The membranes were processed for immunodetection using the following primary antibodies: rabbit anti-SOD-1 (23 kDa), anti-CAT (60 kDa), anti-GPx-1 (22 kDa), anti-HO-1 (32 kDa), anti-Prx-VI (25 kDa), anti-Trx-1 (12 kDa), anti-Grx 1 (12 kDa), anti-Nrf2 (57 kDa), anti-ER- $\beta$ (56 kDa), and 
anti-ER- $\alpha(66 \mathrm{kDa})$. Binding of primary antibodies was detected with secondary antibodies conjugated to horseradish peroxidase, and membranes were developed using chemiluminescence. The autoradiographs were analysed quantitatively with an image densitometer software (ImageJ, National Institute of Mental Health, Bethesda, Maryland, USA). The molecular weights of the bands were determined by reference to a standard molecular weight marker (RPN 800 rainbow full range; Bio-Rad, São Paulo, SP, Brazil). The results from each membrane were normalized by $\beta$-tubulin expression.

\section{Statistical analysis}

Data were submitted to the Kolmogorov-Smirnov normality test. The results that showed normal distribution were presented as mean \pm standard deviation. The values from each animal were subjected to a two-way analysis of variance (ANOVA), followed by the Student-Newman-Keuls test. The carbonyls data did not show normal distribution and were shown as the median and interquartile intervals. For this, we used the Kruskal-Wallis multiple comparisons test. The software used to perform the analysis was SigmaPlot version 11.0. An alpha error probability of less than or equal to 0.05 $(P \leq 0.05)$ was considered significant.

\section{Results}

\section{Echocardiographic, hemodynamic, and morphometric analysis}

The acceleration time to eject time ratio (AT/ET) through the pulmonary artery was evaluated to estimate pulmonary vascular resistance (Table 1). No significant changes were seen in this parameter between groups. Echocardiographic images of pulmonary artery flow showed a slight but not significant increase in pulmonary resistance that was demonstrated by the presence of a midsystolic notch in the 
monocrotaline groups (Figure 1). Stroke volume (SV) and cardiac output (CO) were also determined, and no differences were seen between groups (Table 1). Hemodynamic evaluation was performed through RV catheterization to determine the intraventricular pressures (RVSP and RVEDP). No differences were found in RVEDP between groups (Table 1). Based on the RVSP, the pulmonary artery pressure (PAP) was estimated. MCT induced a significant increase in the RVSP and PAP by about $40 \%$, and this effect was independent of ovariectomy (Table 1). The RV hypertrophy index did not show any significant differences between groups $(P<0.05)$. The uterine atrophy induced by ovariectomy was demonstrated by a reduction of $71 \%$ and $67 \%$ in uterine weight in the $\mathrm{O}$ and $\mathrm{OM}$ groups compared to S and SM groups, respectively (Table 1).

\section{Biochemical analysis}

Results from the biochemical analysis performed in RV homogenates are shown in Table 2. The hydrogen peroxide concentration was increased in the MCT groups (SM and $\mathrm{OM}$ ) when compared to their controls ( $\mathrm{S}$ and $\mathrm{O} ; P<0.05)$. An increase of $36 \%$ was seen in the SM group compared to the S group, and of $37 \%$ in the OM group compared to the O group.

NOS activity was reduced by ovariectomy and by MCT $(P<0.05)$. This enzyme exhibited a reduction of $33 \%$ in the SM group, and of $31 \%$ in the O group when compared to the S group, with no difference between the SM and OM groups.

Regarding the antioxidant enzyme activities, SOD showed a similar profile to hydrogen peroxide, exhibiting a significant increase in the groups treated with MCT compared to their control groups. CAT activity was increased in response to MCT by about $47 \%$ in the SM group compared to the S group. GPx was also increased in the 
SM group (52\%) when compared with the S group. Oxidative damage to proteins, as well as oxidative injury to lipids was not different between groups.

\section{Protein expression analysis by Western blot}

Nrf2 protein expression (Figure 2A) was significantly decreased in the ovariectomized groups (O and $\mathrm{OM})$ compared to the controls (S and SM groups) $(P<0.05)$. Ovariectomy also induced a decrease in the peroxiredoxin (Prx-VI) expression (Figure 2B). There was also a significant decrease in Prx-VI expression in the OM group (by 34\%) when compared to the SM group $(P<0.05)$. SOD protein expression was reduced in the ovariectomized groups compared to their controls (Figure $2 \mathrm{C}$ ). In the OM group, SOD protein expression was $46 \%$ lower than in the SM group, while, in the SM group, SOD was $29 \%$ higher than in the S group. CAT and GPx protein expression did not differ between groups (data not shown). Regarding glutaredoxin (Grx-1) expression (Figure 2D), there were no differences between groups.

Hemoxygenase-1 (HO-1) protein expression (Figure 2E) was significantly reduced by $\mathrm{MCT}$ (SM and $\mathrm{OM}$ versus $\mathrm{S}$ an $\mathrm{O}$ groups). A decrease of $63 \%$ in $\mathrm{HO}-1$ expression was seen in the SM group when compared to the S group. However, a rise $(85 \%)$ in $\mathrm{HO}-1$ protein expression in the OM group was observed when compared to the SM group (Figure 2E). Thioredoxin (Trx-1) protein expression (Figure 2F) had a similar response as HO-1, exhibiting a significant decrease $(P<0.05)$ under MCT administration. Trx-1 was decreased by 53\% in the SM group compared to the S group, and it was increased by $30 \%$ in the OM group compared to the SM group.

The protein expression of ER- $\alpha$ (Figure 3A) in RV was significantly increased in both MCT groups $(P<0.05)$. There was an increase of $70 \%$ in the SM group 
compared to the S group. Similarly, MCT increased ER- $\beta$ expression (Figure 3B). However, ovariectomy also had a positive effect on the expression of ER- $\beta$, such that there was an increase of $67 \%$ in the OM group as compared to the $\mathrm{O}$ group.

\section{Discussion}

This study demonstrated that MCT administration to female rats increased hydrogen peroxide concentration in the $\mathrm{RV}$, but induced an adaptive response of the classical antioxidant enzymes in such a way that oxidative damage was not evident in this tissue. Ovariectomy did not produce additional impairment in the development of PAH induced by MCT, possibly because of the recruitment of other non-classical antioxidants, such as hemoxygenase and thioredoxin. This cardioprotection could be related to the activation of ER- $\beta$, which was observed in the OM group, with which both factors were associated.

In this study, pulmonary flow was analysed through echocardiography for the purpose of determining the AT/ET ratio, which is an index of pulmonary vascular resistance. No difference was found in this parameter, nor in SV and CO. In a previous study from our group that utilized male rats, there was a significant reduction in the AT/ET ratio, indicating increased pulmonary vascular resistance (Leichsenring-Silva et al. 2011). In patients, confirmation of the diagnosis is obtained by cardiac catheterization, which is considered the gold standard (Barst et al. 2004). In the present study, PAH was evidenced through the mean pulmonary artery pressure (PAP), which was estimated by RV catheterization. PAP was increased in both groups treated with MCT. These data agree with the study of Koskenvuo et al. (2010), in which pulmonary artery pressure was measured directly by using RV catheterization. In the present study, there was a slight increase in pulmonary pressure in female rats, while this parameter 
was increased by about three times in male rats, as observed in previous reports (Ishikawa et al. 2009, Koskenvuo et al. 2010). Thus, this suggests that the animals in the present study, at this time point, are in a mild pulmonary hypertensive state. Perhaps, over a longer period, a more prominent increase could be observed, as reported by Konskenvuo et al. (2010). This increase in pulmonary pressure seems to be insufficient to induce RV hypertrophy, as was demonstrated in this study, which corroborates previous data from our laboratory (Siqueira et al. 2011). This outcome differed from that observed in male rats, where an evident RV hypertrophy was documented (Colombo et al. 2013). These findings agree with reports showing that female rats develop less PAH in response to MCT than males (Bal et al. 2013). In our study, RV remodelling was verified by morphometric analysis. To complement our geometric remodelling of the cardiac chamber, a histological and echocardiographic assessment of the RV would need to be performed. This is a limitation of our study.

Bilateral ovariectomy was performed, and the effectiveness of this procedure was confirmed by an evident reduction in uterus weight in both ovariectomized groups. However, ovarian hormone withdrawal seems not to have potentiated the hemodynamic changes induced by MCT.

MCT administration produced an increase in the concentration of RV hydrogen peroxide, which is a ROS. The elevation in ROS levels was associated with reduced NOS activity, suggesting lower NO bioavailability. This decrease in NO bioavailability could also be attributed to the interaction of caveolin-1 with eNOS, an effect which has previously been associated with PAH development (Tabima et al. 2012). However, a compensatory response of the classical antioxidant defence system, SOD, CAT and GPx, was noticed. The increase in SOD activity in both MCT groups suggests an elevation in superoxide anion concentration, which is its substrate. This effect could be 
related to the increase in mean pulmonary pressure, which was mild possibly due to the adaptation of classical antioxidant enzymes, as discussed above. These adaptive changes may also be responsible for the absence of oxidative damage in $\mathrm{RV}$, as observed in the lipid peroxidation and carbonyls data. These biochemical responses agree with functional findings that were not further impaired by ovariectomy. A study performed in male rats using MCT demonstrated greater cardiac oxidative damage (Pichardo et al. 1999).

Since the cardioprotective effect of estrogen has been described in many experimental studies (Umar et al. 2011, Lahm et al. 2012), it would be plausible to suppose that estrogen withdrawal could produce a more severe state of pulmonary hypertension. However, the OM group was not additionally impaired. Thus, we investigated whether this cardioprotection could be mediated by the induction of other non-classical antioxidant defences regulated by Nrf2. In our study, there was a reduction in the antioxidant enzyme protein expression in the RV of ovariectomized animals, which was associated with decreased Nrf2 expression. Nrf2 is a transcription factor that, when activated by low ROS levels, is released from the Keap 1 protein and is translocated to the nucleus, binding to the antioxidant response element (ARE). This transcription factor is involved in the transcription of many antioxidant enzymes, such as $\mathrm{Cu} / \mathrm{Zn}-\mathrm{SOD}, \mathrm{CAT}$, and Prx (Yu et al. 2012). Thus, in the same way as described by Yu et al. (2012), estrogen may be associated with increased Nrf2 expression. Our data have shown that the expression of Prx was decreased in ovariectomized animals. This protein works with small concentrations of hydrogen peroxide and has an important role in the inhibition of protein oxidation involved in pathological cardiac remodelling and apoptosis (Xu et al. 2012). The paucity of information in the literature means it is unknown whether estrogen is associated with Prx expression in this model. 
Nevertheless, it is known that Nrf-2 is primarily responsible for Prx transcription (Karihtala et al. 2011). Thus, the action of estrogen on Nrf2 translocation and on the expression of several antioxidant enzymes suggests that Nrf2 may increase the levels of Prx in order to stabilize the redox environment. A similar response was seen in SOD-1 protein expression, which was affected by ovariectomy, and in the subsequent reduction in Nrf2, which plays a cytoprotective and cardioprotective role (Shen et al. 2006).

Estrogen treatment increases the expression of MnSOD in cultured primary cardiomyocytes (Yu et al. 2012). In terms of Grx, CAT (data not shown), and GPx (data not shown) protein expression, no significant changes were seen.

Another antioxidant defence analysed here was hemoxygenase-1 (HO-1) expression, which was decreased by MCT. HO-1 plays an important role in the metabolism of heme, yielding biliverdin, iron, and carbon monoxide. Biliverdin can be reduced to the antioxidant bilirubin by the biliverdin reductase enzyme, decreasing hydroxyl radical formation from the iron of heme (Gozzelino et al. 2010). The study of Yet et al. (1999) suggests that, in the absence of HO-1 (HO-1-null mice), cardiomyocytes have a maladaptive response to hypoxia and subsequent PAH. This data was corroborated by another study that observed the down-regulation of HO-1 associated with PAH and RV failure (Belhaj et al. 2013). Indeed, our results also show a decrease in HO-1 expression in the ovary-intact female rats with PAH (SM group). However, surprisingly, in the ovariectomized rats, HO-1 expression was not decreased. Although the reason for these contradictory results remains unclear, it seems that this adaptation is important to avoid an additional increase in PAH in the OM group. In principle, HO-1 expression can be modulated by the transcription factor Nrf2 (Gozzelino et al. 2010); however, knockout mice for Nrf2 had no decrease in HO-1 expression (Yet et al. 1999). In the present study, the increased HO-1 protein expression 
in the OM group (as compared to SM) may have been stimulated by a Nrf2-independent signalling pathway, since Nrf2 expression did not vary between these two groups. Other transcription factors known to be involved in the regulation of HO-1 expression, such as nuclear factor- $\mathrm{kB}(\mathrm{NF}-\mathrm{\kappa B})$ and activator protein-1 (AP-1) (Alam and Cook 2007), could be responsible for the results observed.

When analysing the expression of thioredoxin, the same profile as HO-1 was observed. Trx-1 contributes to the maintenance of redox balance via its ability to reduce oxidized thiol groups (Xu et al. 2012). In addition, Trx is involved in keeping Prx in its reduced state, which is essential in the metabolization of hydrogen peroxide into water (Karihtala et al. 2011). It has been reported that estrogen can be protective against heart failure and apoptosis induced by angiotensin II by increasing Trx-1 levels (Ebrahimian et al. 2007). In the present study, the association between MCT and ovariectomy maintained not only the Trx-1 levels, but also HO-1, as well as the compensatory response of the classical antioxidants. This cardioprotective effect must be investigated.

We explored whether this cardioprotection could be mediated by the estrogen receptors ER- $\alpha$ and ER- $\beta$. In the present study, there was an increase in ER- $\beta$ expression in the OM group. The activation of ER- $\beta$, but not ER- $\alpha$, produced a decrease in blood pressure in spontaneously hypertensive rats (Jazbutyte et al. 2008). Moreover, the use of raloxifene, which activates ER- $\beta$ more effectively than ER- $\alpha$, attenuated MCT-induced pulmonary hypertension (Nishida et al. 2009). Similarly, a phytoestrogen, genistein, has shown efficacy in mitigating PAH, apparently through ER- $\beta$ (Matori et al. 2012). These reports point to a cardioprotection associated with ER- $\beta$, corroborating the findings of the present study, in which an exacerbation of PAH was not found.

MCT also induced ER- $\alpha$ and this effect was associated with diminished expression of HO-1 and Trx-1, which would be deleterious for the RV. The literature 
suggests a possible interaction between the ESR1 gene, which encodes ER- $\alpha$, and the development of PAH in humans (Rajkumar et al. 2010). However, ER- $\alpha$ activation by estrogen promoted capillary formation and repair of injured vascular beds (Baruscotti et al. 2010). In the present study, there was an increase in ER- $\alpha$ in the RV of the MCT groups ( $\mathrm{SM}$ and $\mathrm{OM}$ ) compared to their controls ( $\mathrm{S}$ and $\mathrm{O}$ ). This could be a compensatory response against decreased tissue perfusion in these animals with PAH and could contribute to maintaining PAP at moderate levels. In experimental models of $\mathrm{PAH}$, there is no consensus in the literature regarding the participation of these estrogen receptors in beneficial or deleterious responses in the development of PAH.

\section{Conclusions}

A compensatory response of HO-1 and Trx-1 was seen when both stimuli (MCT and ovariectomy) were applied to female rats, and this was probably associated with ER- $\beta$ activation. HO-1 and Trx-1 may be involved in the modulation of oxidative stress in the OM group, and this could be responsible, at least in part, for PAH and RV remodelling attenuation. The findings of the present study are relevant for the understanding of gender differences in the pathogenesis of PAH and to clarify the estrogen paradox in terms of oxidative stress. Modulation of HO-1 and Trx-1 appears to be an attractive antioxidant strategy that could be further explored in this experimental model. The use of such therapeutic interventions capable of modulating oxidative stress may offer newer strategies in the prevention, as well as management of PAH patients.

\section{Compliance with Ethical Standards}

The authors declare that there are no conflicts of interest. The authors declare that the experimental procedures were performed taking into consideration the welfare 
of animals and were approved by the Ethics Committee for animal research at the Federal University of Rio Grande do Sul. 
Table 1: Echocardiographic, hemodynamic, and morphometric parameters

\begin{tabular}{lcccc}
\hline Parameters & S & SM & O & OM \\
\hline Echocardiographic parameters & & & & \\
AT/ET (sec/sec) & $0.29 \pm 0.05$ & $0.28 \pm 0.07$ & $0.29 \pm 0.09$ & $0.28 \pm 0.10$ \\
SV (mL) & $0.21 \pm 0.05$ & $0.24 \pm 0.03$ & $0.23 \pm 0.05$ & $0.25 \pm 0.04$ \\
CO (mL/min) & $47.57 \pm 12.07$ & $52.75 \pm 7.54$ & $55.17 \pm 14.34$ & $59.88 \pm 9.58$ \\
Hemodynamic parameters & & & & $3.30 \pm 1.28$ \\
RVEDP (mmHg) & $2.16 \pm 1.06$ & $2.85 \pm 0.49$ & $2.24 \pm 0.81$ & $37.22 \pm 12.14^{\mathrm{bc}}$ \\
RVSP (mmHg) & $25.98 \pm 6.8$ & $35.88 \pm 7.07^{\mathrm{a} b}$ & $25.18 \pm 4.87$ & $3.71 \pm 7.41^{\mathrm{bc}}$ \\
PAP (mmHg) & $17.85 \pm 4.15$ & $23.89 \pm 4.31^{\mathrm{ab}}$ & $17.36 \pm 2.97$ & 24.71 \\
Morphometric parameters & & & & \\
FBW (g) & & & & \\
RV weight (g) & $255.14 \pm 17.38$ & $246.14 \pm 20.24$ & $262.83 \pm 26.72$ & $251.67 \pm 19.93$ \\
RV / FBW (g/g) & $0.148 \pm 0.02$ & $0.154 \pm 0.02$ & $0.152 \pm 0.03$ & $0.166 \pm 0.02$ \\
RV / tibia (g/mm) & $0.58 \pm 0.06$ & $0.63 \pm 0.08$ & $0.58 \pm 0.05$ & $0.67 \pm 0.13$ \\
Uterine weight (mg) & $4.22 \pm 0.68$ & $4.44 \pm 0.44$ & $4.29 \pm 0.54$ & $4.84 \pm 0.76$ \\
\hline
\end{tabular}

Values are expressed as mean $\pm \mathrm{SD}(\mathrm{n}=6-7) . \mathrm{S}=$ sham, $\mathrm{SM}=$ sham + monocrotaline, $\mathrm{O}=$ ovariectomized,$\quad \mathrm{OM}=$ ovariectomized + monocrotaline,$\quad \mathrm{AT} / \mathrm{ET}=$ pulmonary acceleration to ejection time flow ratio, $\mathrm{SV}=$ systolic volume, $\mathrm{CO}=$ cardiac output, $\mathrm{RVEDP}=$ right ventricle end-diastolic pressure, $\mathrm{RVSP}=$ right ventricle systolic pressure, $\mathrm{PAP}=$ pulmonary artery pressure, $\mathrm{FBW}=$ final body weight, $\mathrm{RV}=$ right ventricle. ${ }^{\mathrm{a}} \mathrm{P}<0.05$ versus $\mathrm{S} ;{ }^{\mathrm{b}} \mathrm{P}<0.05$ versus $\mathrm{S}$ and $\mathrm{O} ;{ }^{\mathrm{c}} \mathrm{P}<0.05$ versus $\mathrm{O} ;{ }^{\mathrm{d}} \mathrm{P}<0.05$ versus $\mathrm{S}$ and $\mathrm{SM}$; $\mathrm{P}<0.05$ versus $\mathrm{SM}$. 
Table 2: Oxidative stress parameters

\begin{tabular}{|c|c|c|c|c|}
\hline Parameters & $\mathrm{S}$ & SM & $\mathrm{O}$ & $\mathrm{OM}$ \\
\hline $\mathrm{H}_{2} \mathrm{O}_{2}(\mathrm{nmol} / \mathrm{mg}$ tissue $)$ & $192.7 \pm 45.8$ & $261.9 \pm 58.2^{\mathrm{ab}}$ & $186.1 \pm 80.7$ & $254.4 \pm 72.6^{b c}$ \\
\hline NOS (nmolNO/min/mg prot) & $1.18 \pm 0.43$ & $0.79 \pm 0.15^{\mathrm{ab}}$ & $0.81 \pm 0.22^{\mathrm{d}}$ & $0.57 \pm 0.14^{\mathrm{d} b}$ \\
\hline SOD (U/mg prot) & $9.74 \pm 2.4$ & $11.26 \pm 1.28^{b}$ & $9.99 \pm 1.44$ & $10.92 \pm 2.15^{b}$ \\
\hline CAT (pmol/mg prot) & $19.57 \pm 7.92$ & $28.83 \pm 9.02^{\mathrm{ab}}$ & $21.41 \pm 7.64$ & $25.89 \pm 6.24^{\mathrm{b}}$ \\
\hline GPx (nmol/min/mg prot) & $26.58 \pm 8.59$ & $40.30 \pm 9.04^{\mathrm{ab}}$ & $30.50 \pm 7.13$ & $29.82 \pm 7.22^{b}$ \\
\hline CL (cps/mg prot) & $155364 \pm 33593$ & $174951 \pm 49378$ & $152813 \pm 17798$ & $148942 \pm 32942$ \\
\hline Carbonyls (nmol/mg prot) & $13.8[11.4-14]$ & $13.8[12.3-14.1]$ & $13.9[9.3-14.2]$ & $10.4[8.6-13.4]$ \\
\hline
\end{tabular}

Values are expressed as mean \pm SD $(n=6-7)$. Values of carbonyls were expressed as medians and interquartile intervals. $\mathrm{S}=$ sham, $\mathrm{SM}=$ sham + monocrotaline, $\mathrm{O}=$ ovariectomized, $\mathrm{OM}=$ ovariectomized + monocrotaline, NOS $=$ nitric oxide synthase, $\mathrm{SOD}=$ superoxide dismutase, $\mathrm{H}_{2} \mathrm{O}_{2}=$ hydrogen peroxide, $\mathrm{CAT}=$ catalase, $\mathrm{GPx}=$ glutathione peroxidase, $\mathrm{CL}=$ chemiluminescence. ${ }^{\mathrm{a}} \mathrm{P}<0.05$ versus $\mathrm{S} ;{ }^{\mathrm{b}} \mathrm{P}<0.05$ versus $\mathrm{S}$ and $\mathrm{O} ;{ }^{\mathrm{c}} \mathrm{P}<0.05$ versus $\mathrm{O} ;{ }^{\mathrm{d}} \mathrm{P}<0.05$ versus $\mathrm{S}$ and $\mathrm{SM}$. 


\section{Figure captions:}

Figure 1: Echocardiographic images of pulmonary artery flow 21 days after monocrotaline or saline administration. The arrow represents the flow pattern through the pulmonary artery, featuring a slight increase (non-significant) in pulmonary resistance. $\mathrm{S}=$ sham, $\mathrm{SM}=$ sham + monocrotaline, $\mathrm{O}=$ ovariectomized, $\mathrm{OM}=$ ovariectomized + monocrotaline.

Figure 2: Protein expressions of nuclear factor (erythroid-derived 2)-like 2 (Nrf2) (A), peroxiredoxin (Prx-VI) (B), superoxide dismutase (SOD) (C), glutaredoxin 1 (Grx 1) (D), haem oxygenase-1 (HO-1) (E), and thioredoxin (Trx 1) (F) in the right ventricle of animals in the experimental groups with monocrotaline or saline. Values are expressed as mean $\pm \mathrm{SD}(\mathrm{n}=4-6) . \mathrm{S}=$ sham, $\mathrm{SM}=$ sham + monocrotaline, $\mathrm{O}=$ ovariectomized, $\mathrm{OM}=$ ovariectomized + monocrotaline. ${ }^{\mathrm{a}} \mathrm{P}<0.05$ versus $\mathrm{S} ;{ }^{\mathrm{b}} \mathrm{P}<0.05$ versus $\mathrm{S}$ and $\mathrm{O} ;{ }^{\mathrm{c}}$ $\mathrm{P}<0.05$ versus $\mathrm{O} ;{ }^{\mathrm{d}} \mathrm{P}<0.05$ versus $\mathrm{S}$ and $\mathrm{SM} ;{ }^{\mathrm{e}} \mathrm{P}<0.05$ versus $\mathrm{SM}$.

Figure 3: Protein expressions of estrogen receptor $\alpha(E R-\alpha)(A)$ and estrogen receptor $\beta$ (ER- $\beta$ ) (B) in the right ventricle of animals in the experimental groups with monocrotaline or saline. Values are expressed as mean $\pm \mathrm{SD}(\mathrm{n}=4-6) . \mathrm{S}=$ sham, $\mathrm{SM}=$

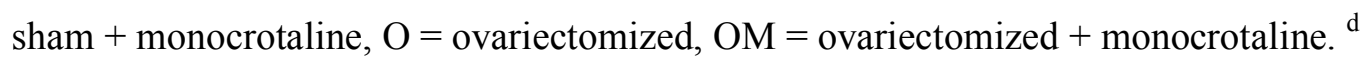
$\mathrm{P}<0.05 \mathrm{~S}$ and $\mathrm{O}$ versus $\mathrm{SM}$ and $\mathrm{OM} .{ }^{\mathrm{a}} \mathrm{P}<0.05$ versus $\mathrm{S} ;{ }^{\mathrm{b}} \mathrm{P}<0.05$ versus $\mathrm{S}$ and $\mathrm{O} ;{ }^{\mathrm{c}}$ $\mathrm{P}<0.05$ versus $\mathrm{O} ;{ }^{\mathrm{d}} \mathrm{P}<0.05$ versus $\mathrm{S}$ and $\mathrm{SM} ;{ }^{\mathrm{e}} \mathrm{P}<0.05$ versus $\mathrm{SM}$. 


\section{References}

Aebi H. 1984. Catalase in vitro. Methods Enzymol 105:121-126.

Alam J, Cook JL. 2007. How many transcription factors does it take to turn on the heme oxygenase-1 gene? Am J Respir Cell Mol Biol . 36(2):166-174.

Badesch DB, Raskob GE, Elliott CG, Krichman AM, Farber HW, Frost AE, et al. 2010. Pulmonary arterial hypertension: baseline characteristics from the REVEAL Registry. 137(2):376-387.

Bal E, Ilgin S, Atli O, Ergun B, Sirmagul B. 2013. The effects of gender difference on monocrotaline-induced pulmonary hypertension in rats. Hum Exp Toxicol 32(7):766774.

Barst RJ, McGoon M, Torbicki A, Sitbon O, Krowka MJ, Olschewski H, et al. 2004. Diagnosis and differential assessment of pulmonary arterial hypertension. J Am Coll Cardiol. 43(12):40S-47S.

Baruscotti I1, Barchiesi F, Jackson EK, Imthurn B, Stiller R, Kim JH, et al. 2010. Estradiol stimulates capillary formation by human endothelial progenitor cells: role of estrogen receptor- $\{$ alpha $\} \mathrm{C} /\{$ beta $\}$, heme oxygenase 1, and tyrosine kinase. Hypertension 56(3):397-404.

Belhaj A, Dewachter L, Kerbaul F, Brimioulle S, Dewachter C, Naeije R, et al. 2013. Heme oxygenase-1 and inflammation in experimental right ventricular failure on prolonged overcirculation-induced pulmonary hypertension. PLoS One 8(7):e69470. Bellanti F, Matteo M, Rollo T, De Rosario F, Greco P, Vendemiale G et al. 2013.Sex hormones modulate circulating antioxidant enzymes: Impact of estrogen therapy. Redox Biol 1(1):340-346. 
Campbell SE, Febbraio MA.2002. Effect of the ovarian hormones on GLUT4 expression and contraction-stimulated glucose uptake. Am J Physiol Endocrin and Metabol 282(5):1139-1146.

Chemla D, Castelain V, Humbert M, Hébert JL, Simonneau G, Lecarpentier Y, et al. 2004. New formula for predicting mean pulmonary artery pressure using systolic pulmonary artery pressure. Chest 126(4):1313-1317.

Colombo R, Siqueira R, Becker CU, Fernandes TG, Pires KM, Valença SS, et al. 2013. Effects of exercise on monocrotaline-induced changes in right heart function and pulmonary artery remodeling in rats. Can J Physiol Pharmacol 91(1):38-44.

Ebrahimian T1, He Y, Schiffrin EL, Touyz RM. 2007. Differential regulation of thioredoxin and $\mathrm{NAD}(\mathrm{P}) \mathrm{H}$ oxidase by angiotensin II in male and female mice. Journal of hypertension 25(6):1263-1271.

Farhat MY, Chen MF, Bhatti T, Iqbal A, Cathapermal S, Ramwell PW. 1993.

Protection by estradiol against the development of cardiovascular changes associated with monocrotaline pulmonary hypertension in rats. Br J Pharmacol 110(2):719-723. Flohé L \& Gunzler WA. 1984. Assay of glutathione peroxidase. Methods Enzymol 105:114-121.

Giaid A, Yanagisawa M, Langleben D, Michel RP, Levy R, Shennib H et al. 1993. Expression of endothelin-1 in the lungs of patients with pulmonary hypertension. $\mathrm{N}$ Engl J Med 328(24):1732-1739.

Gonzalez Flecha B, Llesuy S, Boveris A. 1991. Hydroperoxide-initiated chemiluminescence: an assay for oxidative stress in biopsies of heart, liver, and muscle. Free Radic Biol Med 10(2):93-100.

Gozzelino R, Jeney V, Soares MP. 2010. Mechanisms of cell protection by heme oxygenase-1. Annu Rev Pharmacol Toxicol 50:323-354. 
Hu LW, Benvenuti LA, Liberti EA, Carneiro-Ramos MS, Barreto-Chaves ML. 2003. Thyroxine-induced cardiac hypertrophy: influence of adrenergic nervous system versus renin-angiotensin system on myocyte remodeling. Am J Physiol Regul Integr Comp Physiol 285(6):1473-1480.

Humbert M, Sitbon O, Chaouat A, Bertocchi M, Habib G, Gressin V, et al. 2010. Survival in Patients with Idiopathic, Familial, and Anorexigen-Associated Pulmonary Arterial Hypertension in the Modern Management Era. Circulation 122:156-163. Ishikawa M, Sato N, Asai K, Takano T, Mizuno K. 2009. Effects of a Pure $\alpha / \beta$ Adrenergic Receptor Blocker on Monocrotaline-Induced Pulmonary Arterial Hypertension With Right Ventricular Hypertrophy in Rats. Circ J 73:2337-2341. Jazbutyte V1, Arias-Loza PA, Hu K, Widder J, Govindaraj V, von Poser-Klein C, et al. 2008. Ligand-dependent activation of ER $\beta$ lowers blood pressure and attenuates cardiac hypertrophy in ovariectomized spontaneously hypertensive rats. Cardiovasc Res 77:774-781.

Karihtala P, Kauppila S, Soini Y, Arja JV.2011. Oxidative stress and counteracting mechanisms in hormone receptor positive, triple-negative and basal-like breast carcinomas. BMC Cancer 11:262.

Koskenvuo JW1, Mirsky R, Zhang Y, Angeli FS, Jahn S, Alastalo TP et al. 2010. A comparison of echocardiography to invasive measurement in the evaluation of pulmonary arterial hypertension in a rat model. Int J Cardiovasc Imaging 26(5):509518. Laemmli UK. 1970. Cleavage of structural proteins during the assembly of the head of bacteriophage T4. Nature 227:680-685. 
Lahm T, Albrecht M, Fisher AJ, Selej M, Patel NG, Brown JA et al. 2012. 17betaEstradiol attenuates hypoxic pulmonary hypertension via estrogen receptor-mediated effects. Am J Respir Crit Care Med 185(9):965-980.

Leichsenring-Silva F, Tavares AM, Mosele F, Berger B, Llesuy S, Belló-Klein A. 2011. Association of the time course of pulmonary arterial hypertension with changes in oxidative stress in the left ventricle. Clin Exp Pharmacol Physiol 38(12):804-810.

Lowry OH, Rosebrough AL, Farr AL \& Randall R. 1951. Protein measurement with the Folin phenol reagent. J Biol Chem 193:265-275.

Ludke AR1, Mosele F, Caron-Lienert R, Ribeiro MF, Partata W, Llesuy S, et al. 2010. Modulation of monocrotaline-induced cor pulmonale by grape juice. J Cardiovasc Pharmacol 55(1):89-95.

Marcondes FK, Bianchi FJ, Tanno AP. 2002. Determination of the estrous cycle phases of rats: some helpful considerations. Braz J Biol 62:609-614.

Marklund S. 1985. Pyrogallol autoxidation. In: Greenwald RA (ed) Handbook of Methods for Oxygen Radical Research. CRC Press, Boca Raton, FL, USA 243-247. Martin YN \& Pabelick CM. 2014. Sex Differences in the Pulmonary Circulation: implications for pulmonary hypertension. Am J Physiol Heart Circ Physiol 306(9):1253-1264.

Massafra C, Gioia D, De Felice C, Picciolini E, De Leo V, Bonifazi M et al. 200. Effects of estrogens and androgens on erythrocyte antioxidant superoxide dismutase, catalase and glutathione peroxidase activities during the menstrual cycle. J Endocrinol 167(3):447-452.

Matori H, Umar S, Nadadur RD, Sharma S, Partow-Navid R, Afkhami M. et al. 2012.Genistein, a soy phytoestrogen, reverses severe pulmonary hypertension and prevents right heart failure in rats. Hypertension 60(2):425-430. 
Nishida M, Hasegawa Y, Tanida I, Nakagawa E, Inaji H, Ohkita M, et al. 2009.

Preventive effects of raloxifene, a selective estrogen receptor modulator, on monocrotaline-induced pulmonary hypertension in intact and ovariectomized female rats. Eur J Pharmacol 614(1-3):70-76.

Pichardo J, Palace V, Farahmand F, Singal PK. 1999. Myocardial oxidative stress changes during compensated right heart failure in rats. Mol Cell Biochem 196:51-57. Pick E \& Keisari Y. 1980. A simple colorimetric method for the measurement of hydrogen peroxide produced by cells in culture. J Immunol Methods 38(1-2):161-170. Rabinovitch M. 2011. Pathobiology of pulmonary hypertension. Extracellular matrix. Clin Chest Med 22(3):433-449.

Rabinovitch M. 2012. Molecular pathogenesis of pulmonary arterial hypertension. J Clin Invest 122(12):4306-4313.

Raghvendra KD, Stevan PT and Edwin KJ. 2004. Cardiovascular Pharmacology of Estradiol Metabolites. JPET 308:403-409.

Rajkumar R, Konishi K, Richards TJ, Ishizawar DC, Wiechert AC, Kaminski N,. et al. 2010. Genome wide RNA expression profiling in lung identifies distinct signatures in idiopathic pulmonary arterial hypertension and secondary pulmonary hypertension. Am J Physiol Heart Circ Physiol. 298(4):1235-1248.

Reznick AZ, Packer L. 1994. Oxidative damage to proteins: spectrophotometric method for carbonyl assay. Methods Enzymol 233:357-363.

Rudski LG, Lai WW, Afilalo J, Hua L, Handschumacher MD, Chandrasekaran K, et al. 2010. Guidelines for the echocardiographic assessment of the right heart in adults: a report from the American Society of Echocardiography endorsed by the European Association of Echocardiography, a registered branch of the European Society of 
Cardiology, and t. Journal of the American Society of Echocardiography: official publication of the American Society of Echocardiography 23(7):685-713.

Ruiz-Larrea MB, Leal AM, Martin C, Martinez R, Lacort M. 1997. Antioxidant action of estrogens in rat hepatocytes. Rev Esp Fisiol 53(2):225-229.

Shen X, Zheng S, Metreveli NS, Epstein PN. 2006. Protection of cardiac mitochondria by overexpression of MnSOD reduces diabetic cardiomyopathy. Diabetes 55(3):798805.

Siqueira R, Campos C, Colombo R, Becker CU, Fernandes TR, Araújo AS et al. 2011. A. Influence of estrogen on pulmonary arterial hypertension: role of oxidative stress. Cell Biochem Funct 29(7):543-548.

Tabima DM, Frizzell S \& Gladwin MT. 2012. Reactive oxygen and nitrogen species in pulmonary hypertension. Free Radic Biol Med 52(9):1970-1986.

Takano H, Zou Y, Hasegawa H, Akazawa H, Nagai T, Komuro I. 2003. Oxidative stress-induced signal transduction pathways in cardiac myocytes: involvement of ROS in heart diseases. Antioxid Redox Signal 5(6):789-794.

Tofovic SP, Zhang X, Jackson EK, Dacic S, Petrusevska G. 2006. 2-Methoxyestradiol mediates the protective effects of estradiol in monocrotaline-induced pulmonary hypertension. Vascul Pharmacol 45(6):358-367.

Umar S, Iorga A, Matori H, Nadadur RD, Li J, Maltese F et al. 2011. Estrogen rescues preexisting severe pulmonary hypertension in rats. Am J Respir Crit Care Med 184(6):715-723.

Urboniene D1, Haber I, Fang YH, Thenappan T, Archer SL. 2010. Validation of highresolution echocardiography and magnetic resonance imaging vs. high-fidelity catheterization in experimental pulmonary hypertension. Am J Physiol Lung Cell Mol Physiol 299(3):401-412. 
Valdez LB, Zaobornyj T, Boveris A. 2005. Functional activity of mitochondrial nitric oxide synthase. Methods in Enzymol. 396:444-455.

Waxman AB, Zamanian RT. 2013. Pulmonary arterial hypertension: new insights into the optimal role of current and emerging prostacyclin therapies. Am J Cardiol 111:1-16. Xu J, Li T, Wu H, Xu T. 2012. Role of thioredoxin in lung disease. Pulm Pharmacol Ther 25(2):154-162.

Yet SF, Perrella MA, Layne MD, Hsieh CM, Maemura K, Kobzik L,et al. 1999. Hypoxia induces severe right ventricular dilatation and infarction in heme oxygenase-1 null mice. J Clin Invest 103(8):23-29.

Yu J, Zhao Y, Li B, Sun L, Huo H. 2012.17beta-estradiol regulates the expression of antioxidant enzymes in myocardial cells by increasing Nrf2 translocation. J Biochem Mol Toxicol 26(7):264-269.

Zhang T, Liang X, Shi L, Wang L, Chen J, Kang C et al. 2013. Estrogen receptor and PI3K/Akt signaling pathway involvement in S-(-)equol-induced activation of Nrf2/ARE in endothelial cells. PLoS One 19;8(11):e79075. 
Figure 1
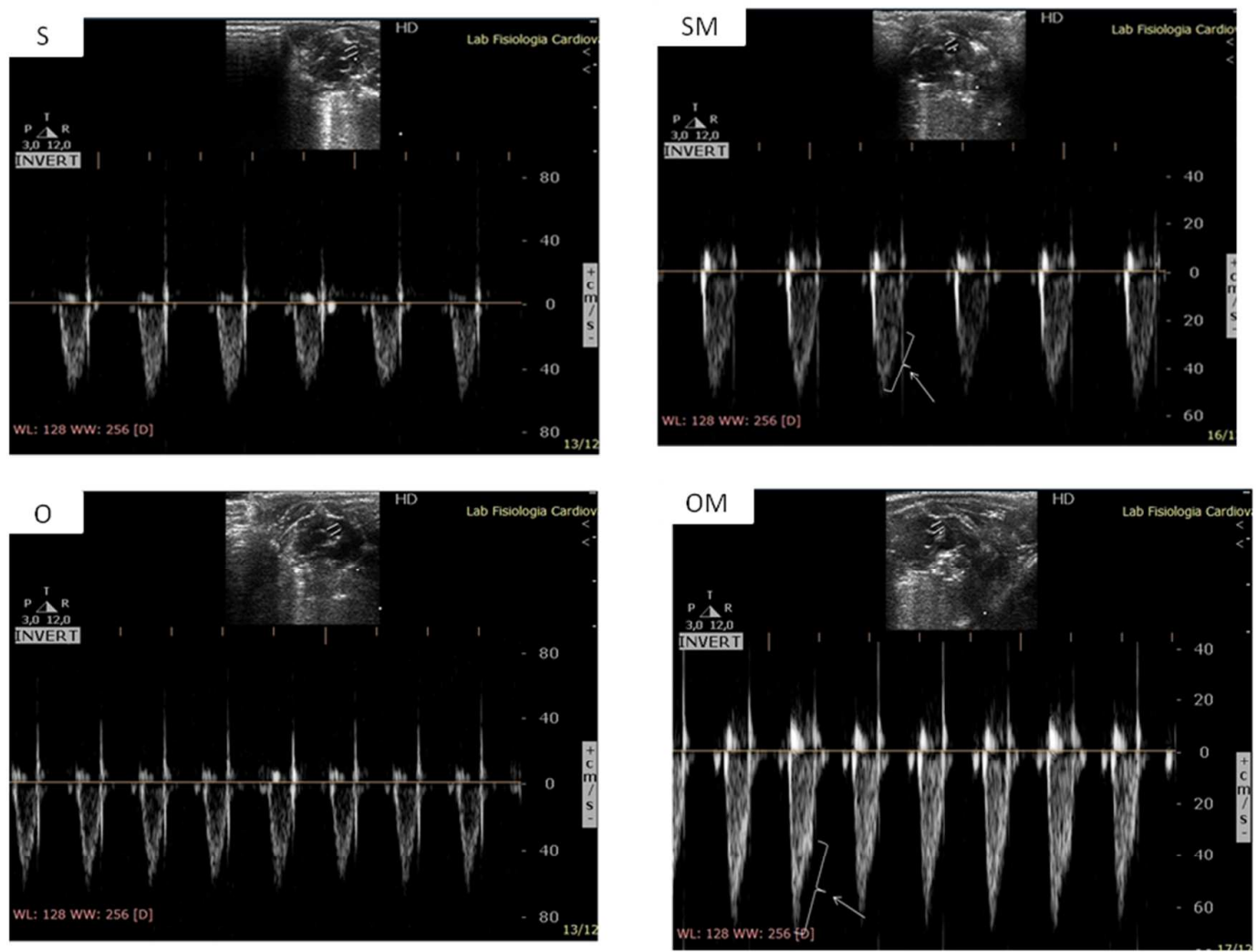
Figure 2

A
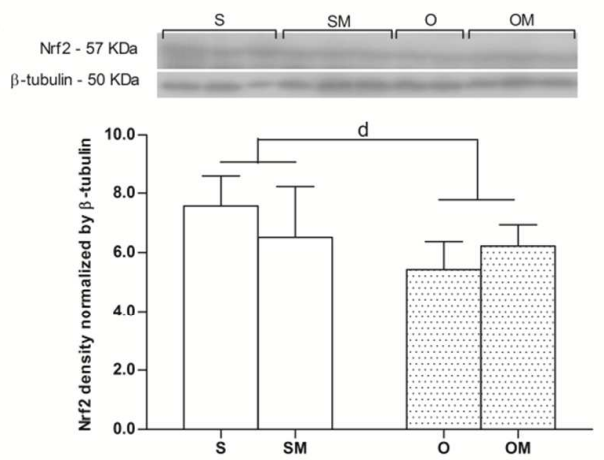

C
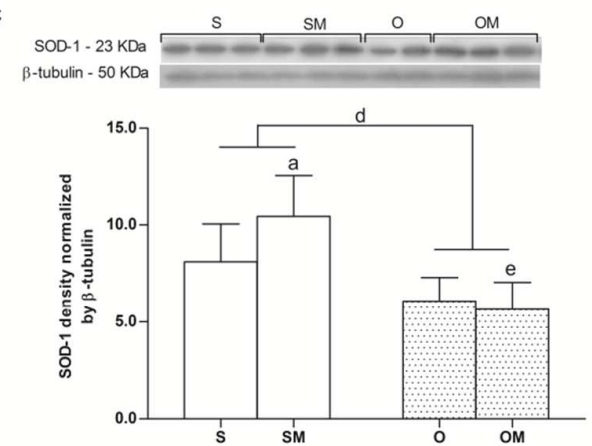

E

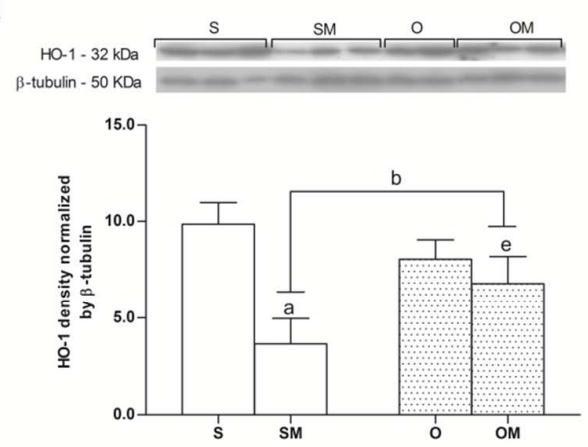

B
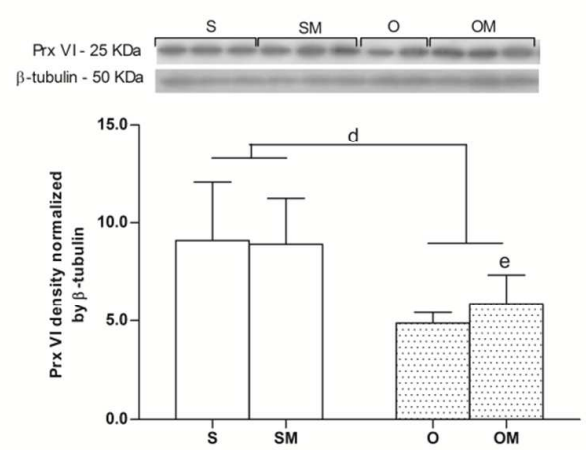

D

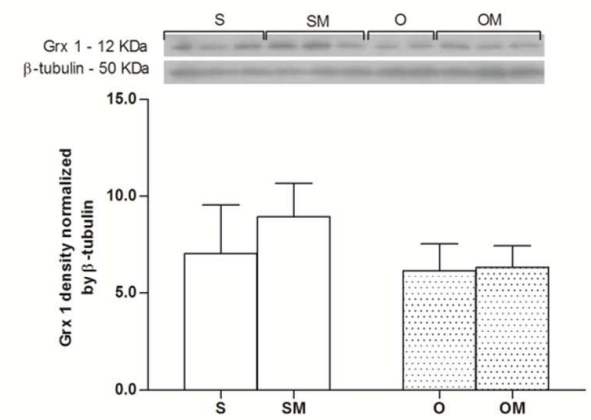

$\mathrm{F}$
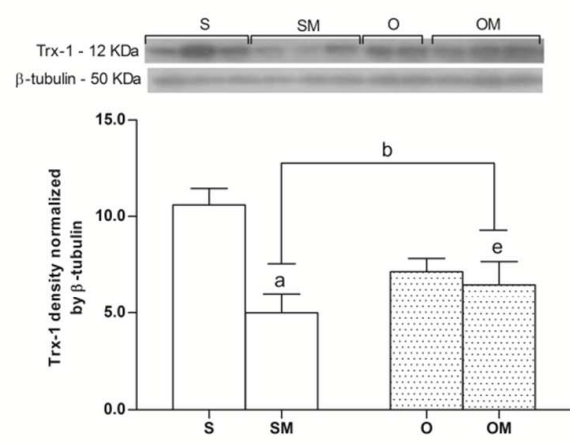
Figure 3

A
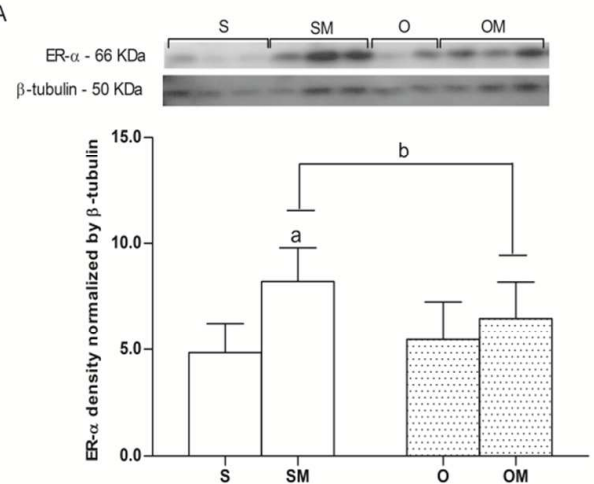

B

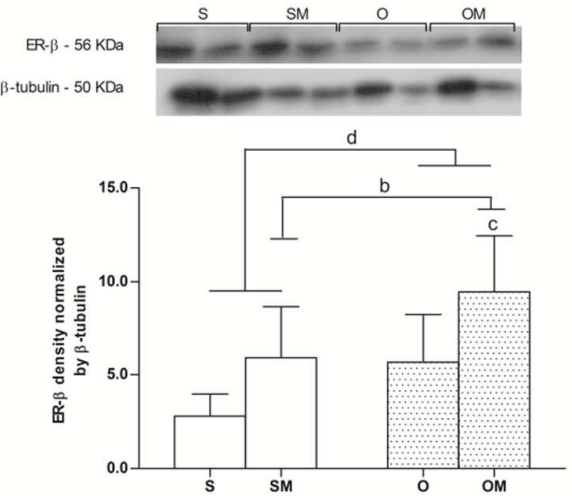

